Matthias Jahn

Zur Rechtswirklichkeit der Pflichtverteidigerbestellung 



\section{Matthias Jahn}

\section{Zur Rechtswirklichkeit der Pflichtverteidiger- bestellung}

Eine Untersuchung zur Praxis der Beiordnung durch den Strafrichter nach $\S 140$ Abs. 1 Nr. 4 StPO in der Bundesrepublik Deutschland

\section{Von \\ Dr. Matthias Jahn}

Inhaber des Lehrstuhls für Strafrecht, Strafprozessrecht, Wirtschaftsstrafrecht und Rechtstheorie an der Goethe-Universität Frankfurt am Main und Richter am Oberlandesgericht

mit den Mitarbeiterinnen und Mitarbeitern der Forschungsstelle für Recht und Praxis der Strafverteidigung (RuPS)

und einem Vorwort von Rechtsanwalt Dr. Werner Leitner

\section{DE GRUYTER}


ISBN 978-3-11-036402-6

e-ISBN 978-3-11-036407-1

Bibliografische Information der Deutschen Nationalbibliothek

Die Deutsche Nationalbibliothek verzeichnet diese Publikation in der Deutschen Nationalbibliografie; detaillierte bibliografische Daten sind im Internet über http://dnb.d-nb.de abrufbar.

(C) 2014 Walter de Gruyter GmbH, Berlin/Boston Druck: Hubert \& Co. GmbH \& Co. KG, Göttingen

๑) Gedruckt auf säurefreiem Papier

Printed in Germany

www.degruyter.com 